Carol Nachman Award for Rheumatology 1997

This international prize will be awarded annually for outstanding research in the field of rheumatology. It is endowed with DM 75000.

Deadline for submissions: 31 October 1996.

Further information is available from: Prof Dr med D Maas, Rheumaklinik I, Aukamm-Allee 39, 65191 Wiesbaden, Germany.

\section{The Volvo Awards for Low Back Pain Research 1997}

To encourage research in low back pain, the Volvo Company of Göteborg, Sweden, this year will again sponsor three prizes of US $\$ 9000$ each, to be awarded competitively on the basis of scientific merit in one or more of the following areas: Clinical studies; Bioengineering studies; Studies in other areas of basic science.

Papers submitted must contain original material in the form of a complete report (including original illustrations), not previously published or submitted for publication, and should be in English, in a form suitable for submission to a scientific journal as an original paper. Multiple authorship is acceptable. The manuscript must not exceed 30 typewritten pages (references and tables included) of text no smaller than 10pt and must be double spaced. Ethics committee approval is necessary for all animal studies and controlled clinical studies.

Deadline for submissions: 2nd December 1996. Articles will not be accepted by Fax.

One original and 5 full copies (including illustrations) of each paper, giving full address, telephone and fax number of the author(s), must be submitted to: Professor Alf Nachemson (Chairman, Board of Referees), Department of Orthopaedics, Sahlgren Hospital, S-413 45 Göteborg, Sweden.

One of the authors should be prepared, at his own expense, to attend the meeting of the International Society for the Study of the Lumbar Spine, Singapore, 2-6 June 1997, to present the paper and receive the award.

\section{Forthcoming events}

18-21 Aug 4th European Conference on Pediatric Rheumatology, Helsinki, Finland

Deadline for abstracts: 15 March 1996.

Contact: Pediatric Rheumatology '96, Congress Management Systems, PO Box 151, FIN-00141 Helsinki, Finland. Tel: +3580175 355. Fax: $+3580170122$

7-10 Sep EULAR Course on the Scientific Basis of Rheumatology, Oxford

Contact: Mr F Wyss, EULAR Secretariat, Witikonerstrasse 15, CH-8032 Zurich, Switzerland. Tel: +4113839690. Fax: +4113839810

11-15 Sep 3rd EULAR Postgraduate Course in Rheumatology, Oxford

Contact: $\mathrm{Mr} \mathrm{F}$ Wyss, EULAR Secretariat, Witikonerstrasse 15, CH-8032 Zurich, Switzerland. Tel: +41383 9690. Fax: +4113839810

13-15 Sep III European Conference on Systemic Lupus Erythematosus, Pisa, Italy

Contact: Organising Committee, Dr S Bombardieri, c/o Clinical and Experimental Rheumatology, via Santa Maria 31, 56126 Pisa, Italy. Tel: +3950 40124. Fax: +3950502299

19-20 Sep Heberden Round, Dr M Seifert, Imperial College, London

Contact: British Society for Rheumatology, Anne Mansfield, Deputy General Secretary, 41 Eagle Street, London WC1R 4AR. Tel: 0171 2423313. Fax: 01712423277

19-21 Sep 6th International Symposium for Health Professionals in Rheumatology, Leuven, Belgium Contact: Mrs J Cartois, Rheumatology Secretariat, UZ Pellenberg, Weligerveld 1, 3212 Pellenberg, Belgium. Tel: 3216 338720. Fax: 3216338724

7-10 Oct IX EULAR Symposium: New Approaches in the Treatment of Rheumatic Diseases, Madrid, Spain Contact: Secretariat, EULAR '96 Symposium, c/Serrano 240, E-28016 Madrid, Spain. Tel: +34145761 12. Fax: +3414570173

10-11 Oct 7th International Conference on Behçet's Disease, Tunis

Contact: Dr M Hamza, Professor of Rheumatology, BP 45, El Menzah 1014, Tunisia. Fax: 2161569283

18-22 Oct American College of Rheumatology 60th AGM, Orlando

Contact: American College of Rheumatology, Ron F Olejko, Director, Conferences and Meetings, 60 Executive Park South, NE, Suite 150, Atlanta, Georgia 30329, USA. Tel: 4046333777. Fax: 4046331870

12-15 Nov 4th Jenner Glycoimmunology Meeting, Athens, Greece

Contact: Philippa Weitz, The Conference Unit, Department of Mental Health Sciences, St George's Hospital Medical School, Cranmer Terrace, London SW17 0RE. Tel: +44 0181725 5534. Fax: +440181725 3390.e.Mail: p.weitz@sghms.ac.uk

In 1997 23-25 Apr

\section{BSR XIVth AGM, Harrogate}

Contact: Ms Anne Mansfield, Deputy General Secretary, 41 Eagle Street, London WC1R 4AR. Tel: 0171242 3313. Fax: 01712423277

21-25 May Fourth International Symposium on the Immunotherapy of the Rheumatic Diseases, Cyprus

Contact: Symposium Secretary, Rheumatology Unit, 4th Floor Hunt's House, Guy's Hospital, London SE1 9RT, United Kingdom. Tel: 0171 955 4394. Fax: 01719552472

8-13 June

XIX ILAR Congress of Rheumatology, Singapore Contact: ILAR '97 Secretariat, Communication Consultants, 336 Smith Street, \#06-302, New Bridge Centre, Singapore 0105, Republic of Singapore. Tel: 65227 9811. Fax: 652270257

11-12 Sep

BSR Heberden Round, Belfast

Contact: Ms Anne Mansfield, Deputy General Secretary, 41 Eagle Street, London WC1R 4AR. Tel: 0171242 3313. Fax: 01712423277

9-13 Nov 61st American College of Rheumatology AGM, Washington DC, USA

Contact: Ronald F Olejko, Director of Conferences and Meetings, 60 Executive Park South, Suite 150, Atlanta, Georgia 30329, USA. Tel: 404 633 3777. Fax: 4046331870 